$\mathbb{P}$ periodica polytechnica

Architecture

40/2 (2009) 55,63

doi: 10.3311/pp.ar.2009-2.02

web: http://www.pp.bme.hu/ar

(c) Periodica Polytechnica 2009

RESEARCH ARTICLE

\section{Making design concepts in the nineties. Theoretical models of UN Studio}

Zoltán Bun

Received 2010-02-18

\begin{abstract}
Attending to the thinking of the second half of the twentieth century there has been a shift from the related-causal image of science to a kind of classification (the examination of local singularities), from closed disciplines to their in-betweenness, from abstract views to pragmatic, then in the territory of architecture from the direct representation of drawings to generativeorganisational model of a diagram, from reactive-post-critical theory to a proactive and productive one. Pluralism and relativity has taken the place of dominating and universal modes of thought, discrete-networked models have been playing a leading role beside continuous-linear ones, as have digital aspects beside analogue ones, as blob forms beside boxes. The analysis of this change in the section of the 1990s can be made by the case study of the oeuvre of UN Studio. The architecture of Ben van Berkel and Caroline Bos is important as it is the key example of the process of dissolving theory in practice. Illustrating their imagination, buildings are being constructed parallel with the intended evolution and self-critical concepts of design and state of architect.
\end{abstract}

\section{Keywords}

immanence $\cdot$ diagram $\cdot$ non-standard and hybrid models $\cdot$ proactive theory $\cdot$ singularity

\section{Acknowledgement}

The essay was written with the assistance of the research program OTKA 72671 under the title 'Active theory. The changing role of architectural theory in the Millennium'.

\section{Zoltán Bun}

Budapest Universtity of Technology and Economics, Department of History of Architecture and of Monuments, Múegyetem rkp. 3., Budapest, H-1111, Hungary

e-mail: bunzoltan@gmail.com
At the very end of the 1980s, the previously determinative past that had been incarcerated in the museum and globalisation hand in hand with capitalism were to change gear to turboboost. 'Poststructuralism' was at war with 'postmodernism', both in general and architectural thinking. Following differencephilosophy and other social studies, architectural deconstruction had questioned the logos-centrism of the discipline and it had success and great influence in the fields of liberating various layers of rigid structures and rules. The abstract theory, a kind of 'textual organisation' that meets material world, did not just pose important questions but it caused serious problems itself: theory made an elitist exodus from everyday life, differences emphasised by the emptiness of in-between, built structures had become 'unreadable' or in other words perception has become impossible, forms connoted catastrophic-traumatic images. Therefore first Peter Eisenman, then his disciple Greg Lynn then, keeping step with them, the majority of the 'western' architectural thinkers turned to Gilles Deleuze and partly Bernard Cache to transmit their 'pragmatist', 'pictorial', very complex and freely combinable theory of the fold [5, 7, 9].

According to Stephen Perella all architectural transpositions of difference-philosophies have been still parts of a kind of enlightenment process of the principle [11]. He says that even if the architect knows that he/she has to be critical with mass society and consumerism, as another meaning of 'everyday life', it is problematic to communicate with the 'technologically deconstructed' subjects thanks to the formalist tradition of architecture. Neither the seem-to-be familiar but uproarious and meaningless references of PoMo methods, nor the alienating negations and breakings of DeCon proved to be relevant and enduring enough. What is more, in those ambiguous times computer technologies became organic parts of media-culture and using them in the territory of architecture has created masses of questions up today.

UN Studio is partly the result of these processes, partly an active protagonist. After nine years of practicing as Atelier van Berkel \& Bos United Network Studio 1 was co-founded by the

\footnotetext{
${ }^{1}$ Compare the associations of the name for example with 'unifying spirit' of United Nations (UN). But at the same time 'un-' expresses contrast that's why
} 
Dutch architect Ben van Berkel and art theorist Caroline Bos in 1998, forcing their shift to and commitment to the complicated systems of the contemporary world. Various experts, urban and infrastructural engineers, designers and others were introduced to the design process in the new studio repositioning both horizontally and vertically the architect-designer, the socalled creative artist-like chief. In the same year van Berkel and Bos edited the $23^{r d}$ issue of the ANY Magazine, one of the influential interests of Eisenman's realm. It was about design methods and means with the writings of such important thinkers as Stan Allen, Robert Somol, Brian Massumi or Eisenman himself. The title 'Diagram Work: Data Mechanics for a Topological Age' included the main aspects of the era: analyses of real, measurable and relevant databases were introduced into creating processes and a complex geometrical form deriving from them could have become a new, maybe digital, version of architectural design technique or a kind of architectural answer to the mediated everyday life of the unifying globe.

\section{Threefolded roots}

Between 1985 and 2000 there were, at least, three determinant tendencies parallel with each other that had basic influence on the architectural thinking and practice of van Berkel. These three were the thought-provoking atmosphere of the Architectural Association which, by the way, made the adoption of the theory of Deleuze easier later, the infrastructural-pragmatist atmosphere of the Netherlands and the technical atmosphere of the digital boom.

With the emergence of inter- or multidisciplinary theories of difference the sameness that had been prescribed in a compulsory way by rigid, fixed, logical, closed, determined systems, types or patterns, or namely by a dogmatic-idealistic modernism, lost its exclusive role. Great emphasis was put on the otherness, on constantly differing relations between extremes or poles, on 'transition'. By this model of relativity or 'accidentality' both solid notions and strict rules working among them seemed to be mobile.

Based on this distinction of general thinking models Robert Somol [14] also sees the two directions in 20th century architecture: the geometric- (or graphic-) model and the power-model. Citing remarkable works of Deleuze he distinguishes a postmodernist repetition referring to historicism and a neo-avant-garde one referring to constructivism. The first operates with icons and copies, the second with simulacra. Therefore the first is bound to a typological, known originality and the second to a seriallike one which is continuously differentiating. The first refers to a constant, infinite and static being while the other to a transformational, sequential and dynamic becoming. In the territory of architecture, seeking for the relationship between form and function, the first belongs to Colin Rowe or Christopher Alexander and the second to Bernard Tschumi or Rem Koolhaas, as

unstudio can be understood as the absence of the traditional role of the architect or the chance for unfolding the complexities of today.
Somol says. For the eighties van Berkel's AA had become an 'operational school', under the influence of the power-model of Michel Foucault and with contribution of Tschumi and Koolhaas.

The origin of the theory of Foucault was the Panoptical principle of Jeremy Bentham from 1787. The point of this prisonstructure was the maximal efficiency of the guard: to distribute the mass of bodies in the optimal way to be able to keep them under surveillance and control. Foucault widened this approach to a model or a diagram of the modern power that is always visible and controllable on one hand, therefore it is automated and is able to share the crowd. That is the representative function of the diagram. And on the other hand the behaviour of the subject, and therefore of the crowd, is modified by the 'system' using the means of constant surveillance, punishment and reward. This is the laboratory of the power, the operative function of the diagram. The aim of this kind of power is not the oppression but the controlled running of the system, the adaptation and distribution of the introduced person-data. Hence Foucault called the Panopticon-model machinic and the behaviourdirecting skill of it was spread out to institutions like schools or hospitals: the theory gained a kind of universality. The book of Deleuze about Foucault moved even further by thinking about the diagram as an abstract machine: after this image, form or notion is not determined by its direct function or 'materiality'. The diagram does not differentiate between content and expression: neither programmatic content, nor formal expression can dominate. The system has to be coherent with a much deeper consistence. That's why emphasis has been shifted to the map of inner relations in principle: to open them up, to keep them under surveillance, to guide them and to represent them while keeping them in a constant immanent network.

This approach was used by architects in AA as turning away from the 'rationalist order-keepers' of the sixties and like Aaron Betsky described them as seeking for the connecting points of UN Studio [1]. For the beginning of the eighties he said form was dead, since the faith in grid, reduction and linguistic systems of structuralists drove to the denial of it. Architecture could survive this state only by 'inserting itself into a process of cultural criticism of the city, by becoming conceptual art, or by disappearing into the landscape' [1], p. 8. - as it happened in the deconstructive work of Koolhaas, Tschumi and Zaha Hadid and their students (See Fig. 1). Thus Ben van Berkel joined this alteration of the discipline but he moved on immediately partly by researching pragmatism and diagrammatology, partly owing to his youthful impetus. 'While still a student, Ben resolved to become the most prolific architect of his generation' [15]. According to this self-awareness he did not want just to think about architecture but to build also. Therefore his designs became reality sooner than some of his teachers', the so-called paper generation's of deconstruction.

Not just the realisation of buildings was helped by the Dutch context but some aspects of the design methods also. The in- 


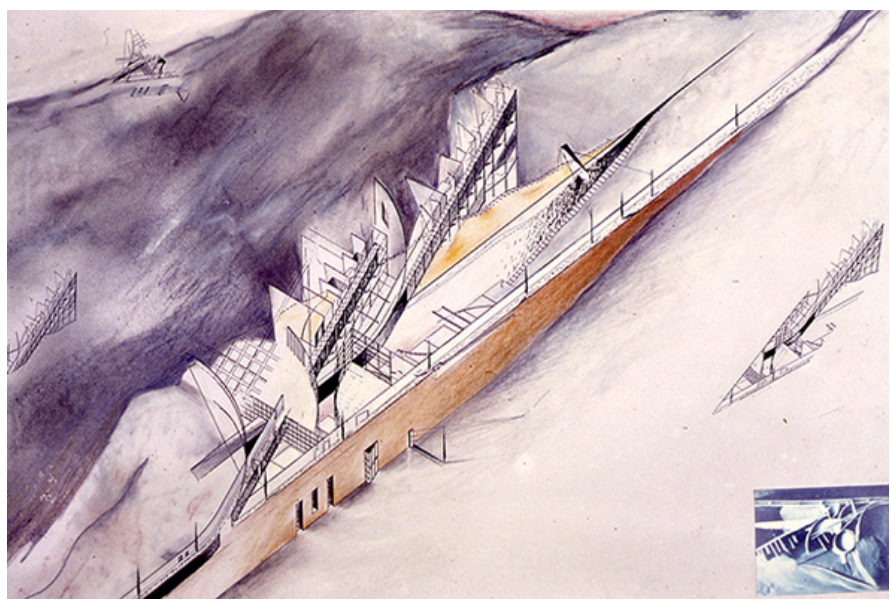

Fig. 1. 'Tourist Settlement' by Ben van Berkel, 1984: http://www. aaschool.ac.uk/PORTFOLI0/pastyears.htm

tersection of cultures and economies owing to the geopolitical position, the quality guaranteed by this economical potency, the maximization (and optimization) of the use of scant territory, the 'artificiality' of nature that is coalescing with cities, the continuous and extensive development after the 'tabula rasa' of the Second World War, the creation of incredibly high levels of infrastructure to serve emerging personal mobility for an on-coming millennium can be mentioned generally. Not just the professional starting of van Berkel was favoured by these but his coevals, the so-called Superdutch generation also. Although both Koolhaas and van Berkel refuse to be ranked in this group, Rem was the path-finder for the young and Ben was one of the leaders of this army.

From the point of view of UN Studio the following factors of 'Superdutchness' are the most important:

1 The rebuilding wave after the Second World War and its local 'modernisation-effect' came to an end in the late 1980s. The Dutch decided to join the international architectural and urban standards and values hence architecture and architects got huge publicity and significance. In the meantime they still had a strong (modern) belief in social 'égalité', which had found a kind of expression earlier in structuralism but was then annulled by the incoming difference-theory spread by the thinkers studying outside of the country. Equality is not equal with sameness but guarantees the chance of being different. Therefore equality in thoughts, structures and forms was represented in interactive discussions with the help of diagrams.

2 In contrast with the international unfolding after 1989, a social revival of the tradition had also begun to rise 'naturally'. Instead of radicalism or extremes, like in the topographical model of Cache, Superdutch tried to find a balance between past and progression, subjectivity and objectivity, value and consumerism. Of course it was not that hard to be 'contemporary' in the context of technology-based and pragmatic plenty. Although this welfare never meant to waste goods, actually it was the purism and rigour of Protestantism, nowadays in the works of van Berkel the sources are used rather in a professional, high-end way than in a sparing one at first sight. That is why, according to Bart Lootsma, the richness of UN Studio's 'Möbius-house' is anonym. (By the way it goes against the homogeneity of the Superdutch-group that Koolhaas had an extremely cheap period, called 'Calcutta-minimalism' his deconstructive experiments.)

3 The importance of infrastructural projects has to be understood in the relations and needs of the hypermodern Netherlands. As a big mount and a big scale of 'artefacts' are being built in the urban landscape their formation has to correspond to this context, so introducing architects with the design process is needed. Close and hierarchy-free co-operations with engineers make it possible for architects like van Berkel both to 'think in infrastructures' and to design infrastructure 'architecturally'. For example the behaviour of materials can be integrated into design this way and bridges or electrical substations can be integrated into urban contexts (see Fig. 2).

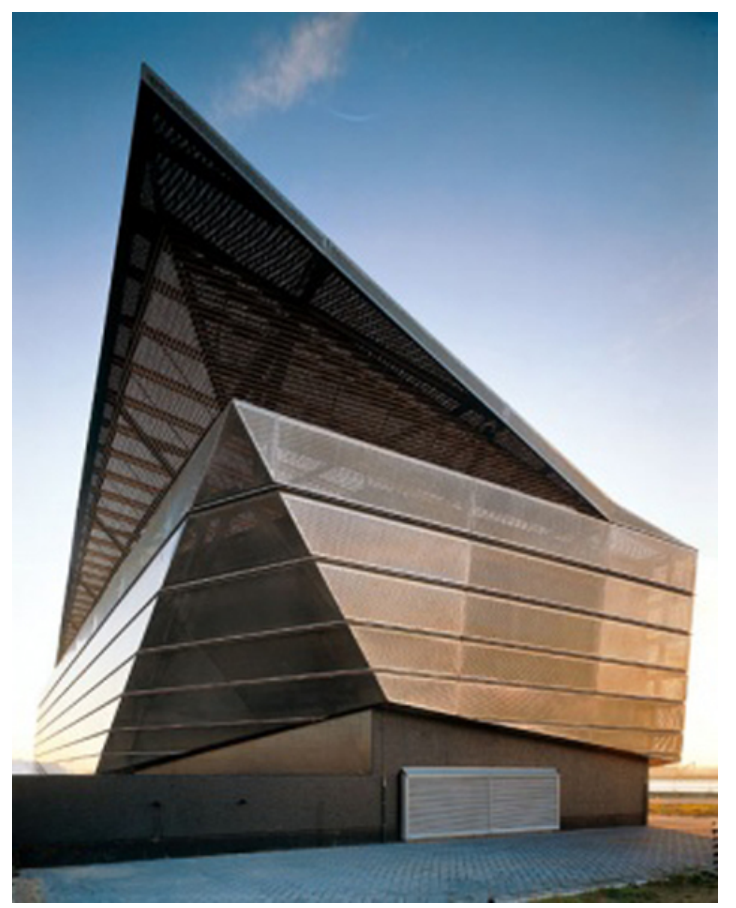

Fig. 2. Piet Hein Tunnel, Amsterdam, 1990-97: Move 1. Imagination, 161.

Without these parameters or in another place, as it will be seen, UN Studio would not have been created, even if the founders protest against any classification like Superdutch.

Furthermore the emplacement among architects interested in digital technology and thinking can be also a relevant classification. The idea of non-standardism and many other theories of these creators are mostly based on Deleuze and his first and most 'authentic' architectural reading by Cache [5]. 22 The approaches linked here are generally more than pure technical methods as Zeynep Mennan pointed out and their importance

\footnotetext{
${ }^{2}$ See Earth Moves and the close relationship between Cache and Deleuze.
} 
can be described in three main issues. First, as a critique of modern thinking, standardisation can be changed by a continuously transforming singularity both in the (architectural) product and in its elements. Second, as a realizable complexity, immanence can be 'created' by the computer which handles complicated architectural programme together with structure and form, and which links the architectural studio with the factory by direct file-managing, and so on. And third, as a shape, it is not relevant anymore if a complex form is evolved during 'conceptualization', because on one hand non-Euclidian geometry can be manufactured as mass-production at a reasonable price, and on the other, shape can be figured easily and in 'real-time' parallel with the concept itself.

In the meantime, the work of UN Studio is a kind of exception among other 'non-standard architects'. Although their projects are not created by analogue techniques, they are not that experimental or educational as others', owing to the pragmatist commitment of van Berkel. Against those, who are mostly thinking in radical 'virtual models' disconnected from the real world, UN Studio uses digital technology in service of materiality and construction, already at the beginning of the design process.

\section{Fields of coherence}

What had been articulated earlier in theory, by Deleuze and other philosophers, 'became reality' owing to the digital technology of the nineties. The rhizomatic network, the virtual activated by the media, the 'visibility of time' is all part of today's life. Many 'contemporary structures' can be handled by both deconstructive and other difference-based techniques. On the other hand, it is possible to select, store, connect, manipulate and visualize information by using the computer. As the goal was in theory, to think about the world as an infinite, non-linear, nonhierarchical and inhomogeneous system which is often affected by chance, in the early works of Ben van Berkel differentiated spaces and elements were related by the method of collage, or by a 'sub-method' of montage, assemblage or bricolage. But the result was not coherent, rather fragmented. Therefore another technique, hybridization, is needed to make seamless structures both in theory and practice. To make relevant hybrids in an extremely complex world a very open and sensitive model had to be found, which would be able to collect and link all necessary data. Architectural inclusiveness is the practical model of the immanent fields of Deleuze which is operated and 'represented' by the instrumental tool of the diagram. Inclusiveness contains materialization and construction, so the diagram guides any formation, any immanent geometry with the help of the computer.

\subsection{Hybridization}

The deconstructive methods and buildings constructed by them already departed from gravity and determination. They were demolishing dogmatic and structural limits and gave chance to the 'stranger'. It is the visualization or manifestation of the world we live in where everything is self-familiar and not totally a stranger. We feel the cosmopolitan homelessness and we do not belong to any 'nation', 'race' or 'identical type' anymore in the global continuity, as the critical aspects refuse the modern universality and homogeneity. The idea of equality makes connections between differences, namely singularities and localities, and according to the model the new image of the world is blurred into a hybrid. Both Jacques Derrida and Deleuze rejected inviolable and finely defined pasts, or closed thus dead archives, hence the socio-cultural 'melting pot' of today can be a relevant space for individualities to feel free from any fetter and be nothing 'typical' but themselves (see Fig. 3).

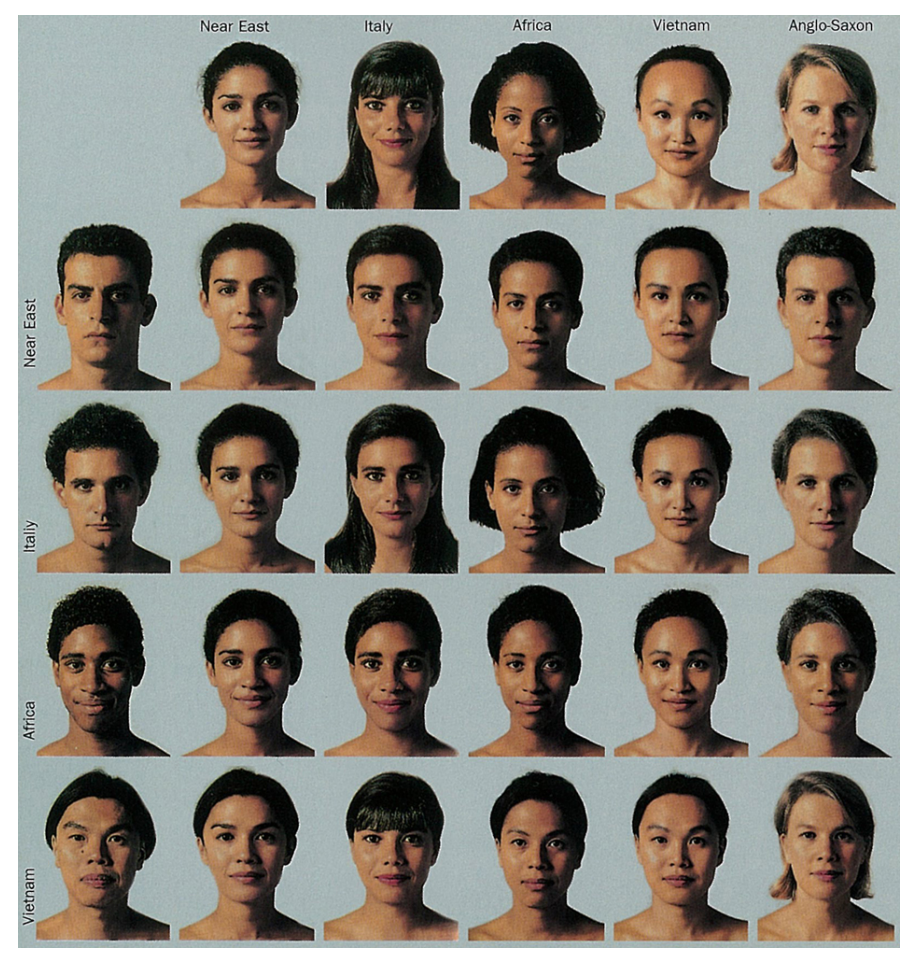

Fig. 3. Detail of 'Hybridization' by Kim Wah: Move 2. Techniques, 78.

So architectural 'hybrid structures have no authentic, recognisable scale, their organisation is geared towards allowing function-related expansion and shrinkage and this results in overlaps and non-determinate spaces that flow into each other [16]. The digital technique of morphing or the graft of Eisenman is suitable for making hybrids. Both of them are 'applications' of the deterritorialized and topographical thinking of Deleuze and Cache, the practical realization of the foldingconcept. The duality of graft and subject, figure and ground, imagination and form, theory and practice disappears. Instead of the fundamentally two-dimensional technique of collage the new model involves three or, counting time in, four dimensions. Time is attached to movement so movement-maps make time visible on one hand, and on the other, sequence of time, or 'duration', frames the design process. According to the topographical model the so-called 'result' cannot be definitive but temporal, the process cannot be finished. The only and perfect solution cannot exist.

The general model of UN Studio, the Manimal (see Fig. 4), 
represents the forces of structural cohesion. Portraits of Chinese men were morphed digitally with the 'portraits' of their own zodiacs. The series shows that our behaviour, personality or even physical appearance is affected by our 'zodiac'. Although this approach could be deterministic, van Berkel reveals this and emphasises the technical creating of the image as it does not represent a state of being but a sequence of 'becoming'.

\subsection{Inclusiveness}

UN Studio applies the principle of 'involving every relevant datum' to achieve hybrid fusion, an intensive structural coherence. In immanence fields of Deleuze there are no independent or universal threads of thoughts but necessary and peremptory nexuses. There is no causality and 'unequivocality', the complex world is building up from a rhizomatic and hierarchy-free network. Distinct or individual parts then are also missing from the architectural concept: the organisation is based 'on one comprehensive gesture incorporating difference'[16]. All data has to have influence on the whole system, viz. program and its 'embodiment' (form) needs to have the same roots (or rather rhizome). If the system is in this kind of equilibrium it can take any form because it is evolving with the program. Hence there is nothing to leave: there are no residues or residual spaces like there are in the InFormationist deconstruction of Tschumi and Koolhaas. This model is against-nothing. There are neither deconstructive voids nor standard wasting of material.

In the work of UN Studio inclusiveness influences two levels: design process and shaping. Today real-time consultation, clean communication and control of different fields of expertises, is helped by technology. Inclusiveness is capable of direct linkage among materials, programmatic systems, mechanics, budget-calculation, etc.: so designing becomes also a hybrid expanded by political, social, economical, infrastructural and other regards and transformed into a non-linear, equal series of collective decisions (eee Fig. 5).

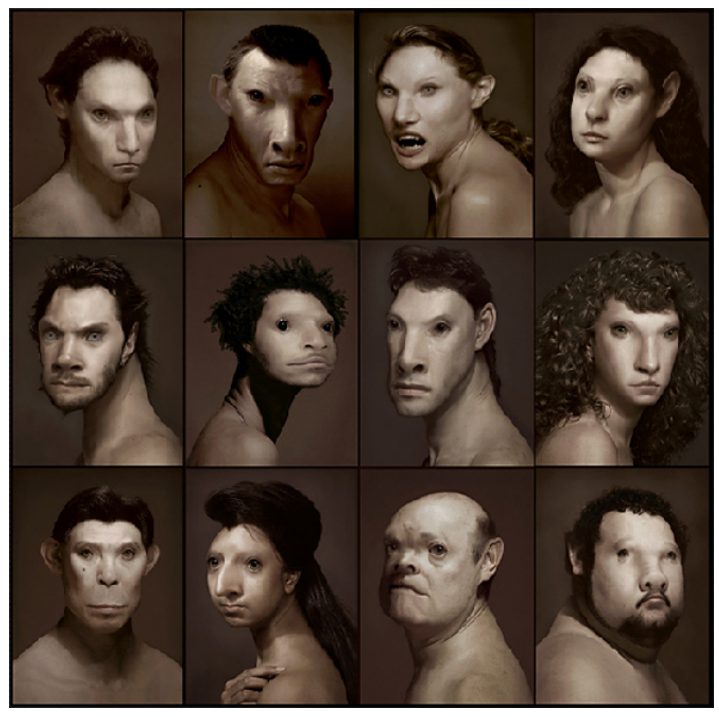

Fig. 4. 'Manimal' by Daniel Lee, 1993: www.daniellee.com/DigitArt.htm

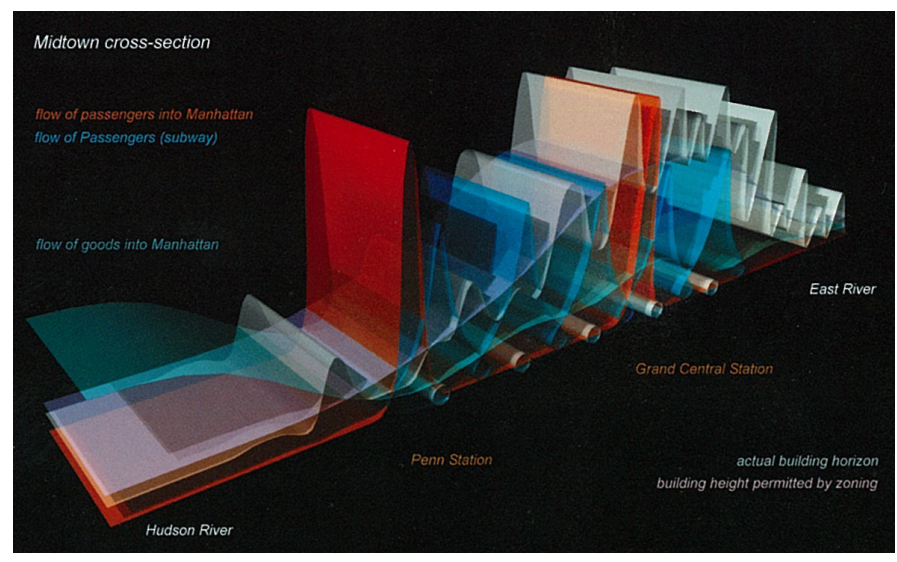

Fig. 5. Inclusive database of IFCCA Competition, New York, 1997: Design Models, 330.

The formal aspect of inclusiveness follows Francis Bacon, and Deleuze again, referring to the concept of 'body without organs'. Instead of a personality identified by a face on the paintings of Bacon there is 'only flesh'. Instead of covering the subject by a 'fake-facade' on the head, the essential organism expresses itself. This body is singular; it differs from both types and extremes. As Cache had pointed out earlier in an architectural body of this kind the duality of a closed-initself mass and a discrete detail cannot exist, actually there are no details. Furthermore, opposed to other architectural 'interpretations' of Deleuze, like the 'semperism' of Cache or the conceptual-theoretical folding of Eisenman, in the work of UN Studio usually there are no supporting structures or facadeskins, tectonics or distinct parts. Only the flesh, a new kind of materiality, exists: in situ, raw, self-compacting reinforced concrete or a non-standard rod-system. Van Berkel prefers the first one, as a kind of immanence and structural rationalism. There is only concrete and the transparency of glass, therefore the differences of structures are missing: no need for details in this topography.

\subsection{Diagram}

To use the inclusive principle and to make the intensive coherence visible during design a mediator device is required. Van Berkel just immediately after the years at AA applied design drawings which were made by a more linear method, but at the same time, they were far away from representative images as appropriate deconstructive anti-illustrations ${ }^{3}$ Fig. 6 The Atelier van Berkel and Bos wanted to get rid of this socalled 'individual-abstract' architecture and decided to move to everyday practice. The problem was, according to them, that the extreme complexity of projects after 1990 could not have been handled by traditional limited and defective representational techniques. The 'final solutions' were unjustified; the cre-

${ }^{3}$ Cf. transformational diagrams of Eisenman, flash sketches of Coop Himmelb(1)au, movie stills of Tschumi, density of drawings of Daniel Libeskind or twisted paintings of Zaha Hadid. 
ating process disappeared especially if architectural deconstruction was really conceptual and hardly understandable by an investor, a 'sub-designer' or a user. Facing the Millennium architects have to act responsibly and rationally during co-operations with decision-makers and others, that is why conviction and effective visualization are inevitably needed. So controlling and operating complexity on one side and representing this immanent 'organism' on the other is the goal of the diagram of UN Studio and the computer is the tool for achieving it.

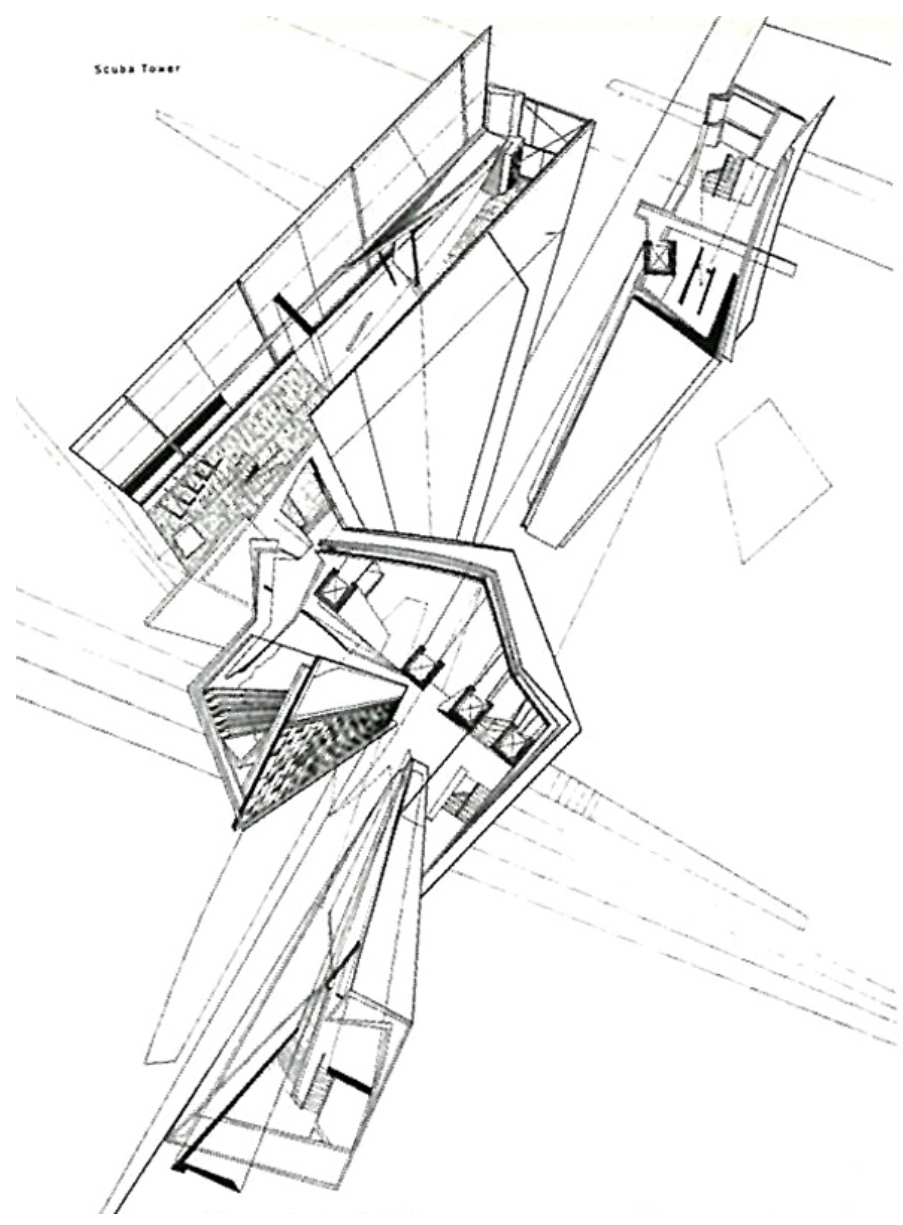

Fig. 6. Docklands, London. Final study project at AA with Hadid, 1987: Design Models, 380.

Although the diagram involved the daily life-cycle of clientcouple in the case of Möbius-house, a concrete form was not generated by the model, even the concrete structure swirls from inside to outside, but rather a space-time continuum, an organisation of spaces was created (See Fig. 7). Van Berkel and Bos applied the panoptical model of Foucault and Deleuze, the aleatoric attitude of Bacon and the topographical weaving of the story of Marcel Proust as an 'abstract machine' or a generator device. Against a pure statistical diagram that works as an inward reduction the Deleuzeian one is inclusive and opened. It is not a representational model but an instrumental technique and a visual device to compress the most information. Program, space and form is organised by this non-exclusive diagram: it is not the only method, so evolving is always necessary.

In opposition to the diagrams of Rowe or Alexander that were not able to escape from existing closed-ideological typologies, all techniques and products of UN Studio are imagined as singularities. Evolving them on one hand makes the capability of retarding to tie types down and on the other it insures avoiding being a cliché against clichés as Deleuze warned of this danger. Meanwhile it is questionable how the models can follow more and bigger constructions nowadays. If products want to be singular in a new kind of mass production, be familiar with each other and structurally different at the same time, would not they be recognizable as a signature of the architect who uses the 'not-that-much different' diagrammatic models. This issue will return especially in the light of the international reputation of diagram-works of UN Studio.

\subsection{Geometry}

For becoming real (actual), during the work with computer and diagrams, mathematical-geometrical models are needed. Primarily the intention of using them is not about searching for forms although it is obvious that they have also a kind of role in shaping, even if van Berkel refuses the 'non-differential' direct connection between thought and figure. The point is that the informational compressing operation of diagram has to create a both theoretical and practical essential structure. It can be a blob or a box, it does not matter whether it stabs or strokes, but since it is an organisational level of 'becoming', form is the jointvariable of the whole incorporating system. Thus striving for a 'good' solution is not attached to a given form but, engaged with immanence, complex problems are controlled by complex models that are visualised by complex geometries which in the most remarkable projects of UN Studio, introducing time and movement to the design process, are 'warped' and non-Euclidean (see Fig. 8. Though this geometry often appears in conceptual models at van Berkel's it disappears in explicated structuralformal level. This is mediated indirectness, however owing to geometrical-organisational complexity, 'multiplicated' or 'intricated' spaces are created in both stabbing and stroking cases.

Neither geometrical complexity would have achieved nor would the conquest of diagram have taken place in the nineties without technical-virtual networks that interlaced everyday life. For van Berkel and Bos the computer was a liberating tool at that time to completely get rid of formal references, catalogues and types of the past and to get closer to contemporary complexity. With the help of the instrumental tool of digital technology 'one could reduce the complexity of the urban environment to data, collect these figures, and form them on the computer itself into coherent forms' [1].

So in Arnhem (see Fig. 9), attached to the redevelopment of the train station, many overlapping programs and traffic problems, ergo different 'landscapes', were handled together in this inclusive, complex way. Between the differences, in the intervals, was the pedestrian movement, it made the organisation fluid. The junctions of the roots are, both programmatically and conceptually and formally, mathematical singularities: the in- 


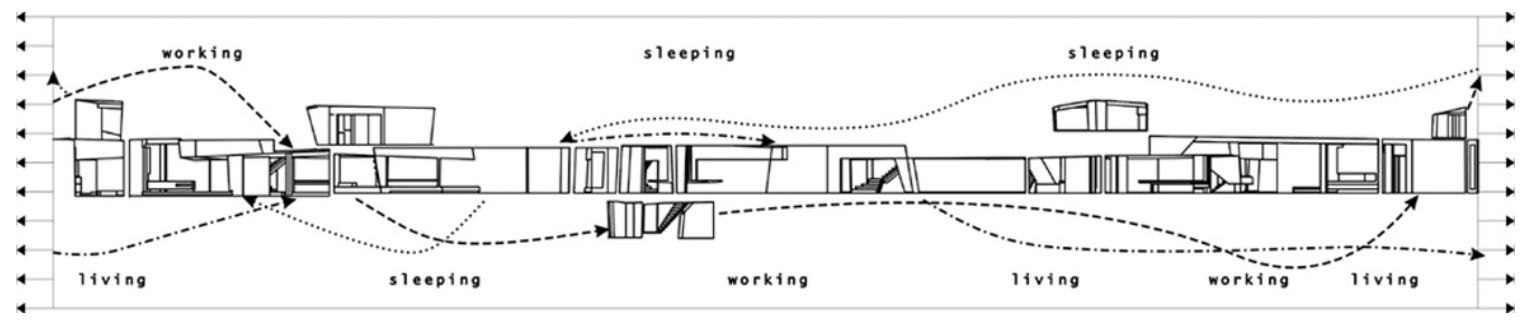

Fig. 7. Möbius-diagram: Design Models, 152-153.

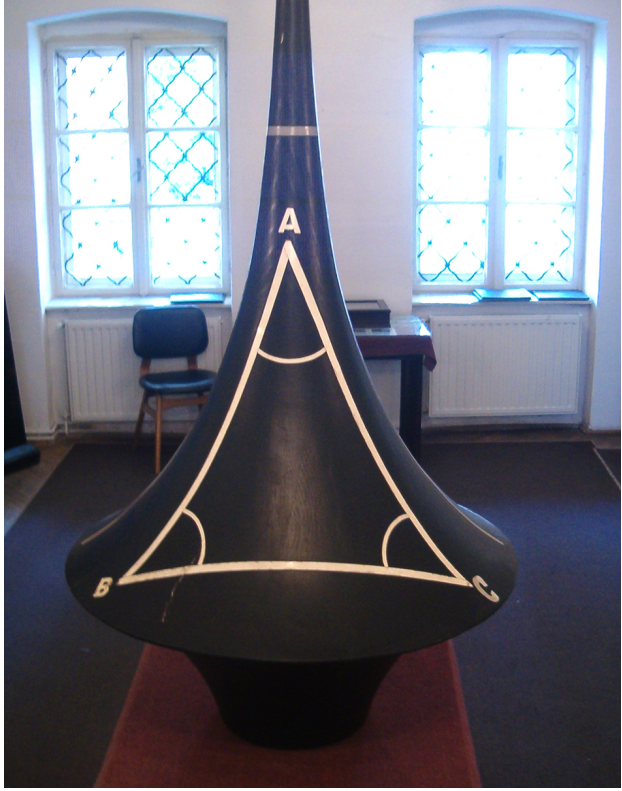

Fig. 8. Warped triangle of János Bólyai: Photo: Zoltán Bun

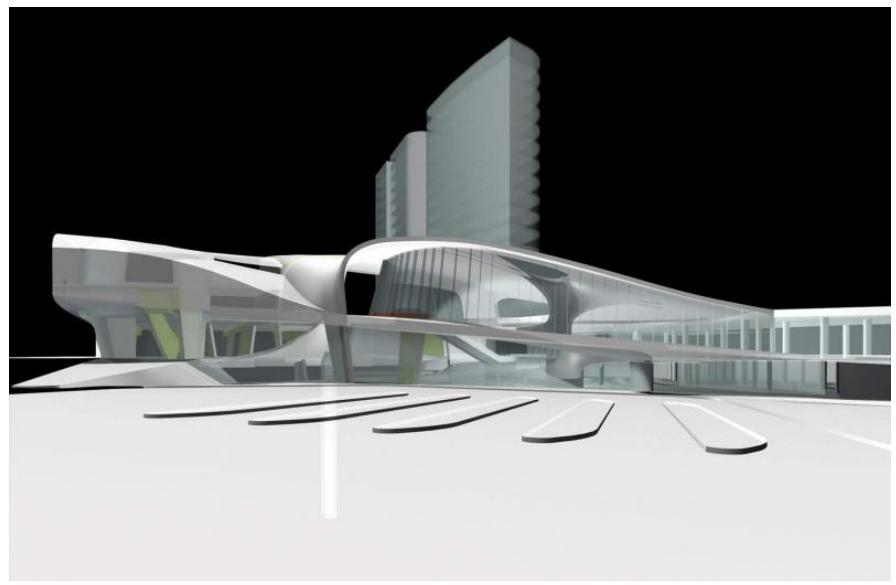

Fig. 9. Arnhem Central, 2000-2012: ArchIdea 34 2006, 5.

flections of Cache. Then trajectory-network, made by arbitrary databases of movement-studies, can become an actual-real landscape by mathematical transformation. The helping model here was the Klein-bottle which is diagrammatic (activator and organizer), pragmatic (based in local conditions) and formally continuous at the same time. The operation and the figure of the building is not a consequence either of the (infrastructural) operation or the aesthetics of the locus but an immanent activation of it in a mediated way. The diagram activates or fertilizes design process which can be then objective and personal, abstract and pragmatic, pre- and after-theoretical, and the organization made from it can be visible and latent, figure and ground, wall and slab, the Euclidean box of an office and a non-Euclidean blob of a passenger terminal.

\subsection{Pro-active theory}

The nineties were also spent with answering architecturally the questions asked by Deleuze, for other architects as Bos says. Hence, eliminating the results of deconstruction and the Hadid-, Himmelb(l)au- or Gehry-like radical or mannerist individuality, van Berkel proclaimed the command of 'no design' which, according to him, made a quasi-automatized process without intended encroachment in the beginning. But it is hard to believe that generative models were building themselves on databases, with regard to the carefully shaped, dynamic, 'late-decon' buildings and the indispensability of guidance or control of the architect in selecting information - as it is the case in the operation of Panopticon.

This era of rational rigour was not too long, perhaps because they kept on reading Deleuze. The goal was then, as a pendulum tendency back to subjectivity, to find a balance between strict and object data and contradictory and instinctive emotions. Van Berkel and Bos proclaimed this time to make architecture 'between art and airport' admitting their appearance in the design process. Like at Bacon's, the diagram of the freshly founded UN Studio in the Millennium is infrastructural on one hand as it can be read as a map of movements: either as an imprint of the unconscious action-painting or the digital transformation of the changing environment. And on the other hand both products are modified personally. Art and airport equals a kind of singularity and measurable pragmatism: so is there anything new under the sun of the discipline?

A few years ago 'expression of concept' was still a posteriori rationalization, according to Bos. 'The compulsive force of legitimising arguments still dominates, even though it represents only a limited interpretation of the complex web of considerations that surrounds the project' [16]. The whole oeuvre of Deleuze 'argued' against this automotive and rigid use of mind and causality, that is why the networked-immanent systems are creative, productive and fictional instead of canting and snivelling on passed texts of history. In the meantime 'architexture' in the most cases has not had practical relevance and practical architecture has not had theoretical support. Theory and practice, imagination and technique, thought and form were generally separated: there were the ideas before embodiment on the side 
of imagination and the Cartesian geometries on the side of materiality. Following then Deleuze, the generation of van Berkel is liberated from history, from references, from catalogues of types and it turns to creative and generative production. Materiality is folded into the fictitious organisational structures of theory: it becomes interactive in its 'behaviour' (see Fig. 10). Material and virtual are engaged by topological geometries, computer and diagram. It makes concept apparent and apprehensible, it makes architectural consciousness visible in the building. Instead of critical and evaluative after-theory or instead of its end, theory became immanent or pro-active.

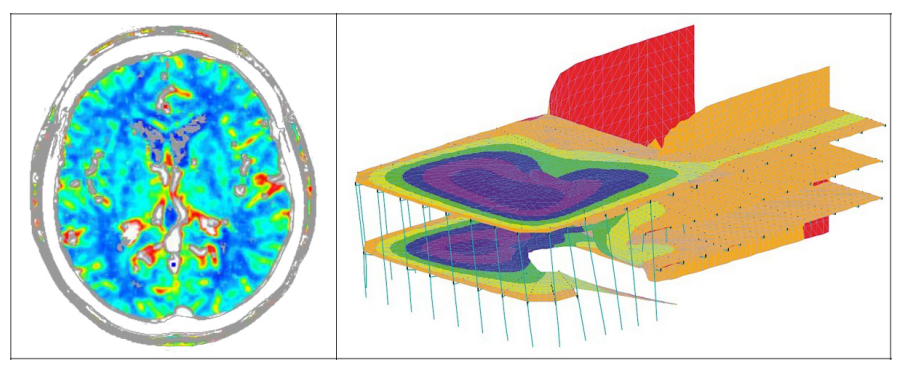

Fig. 10. Operation of brain in comparison with operation of structure of Mumuth, Graz, 1998-2008: Montage: Zoltán Bun

\section{Never-ending story?}

As it has always been, architecture after 2000 still fights about subjectivity and objectivity, it is still under the influence of 'Zeitgeist', it still shelters people and it is still modified by rereadings of archi-texts. But it is inevitable that 'outsider', critical and extensive theory weakened, even passed away, and the collection of archetypical form-structures finally lost its domineering position by the possibility of non-standardization. The work of UN Studio tries to widen the limits of the territory of architecture by implicating difference-theories, Dutch pragmatism and digital development. The most important result of it is a theory that seems to be evolutionary, transparent, democratic and useful.

Arguing for a design decision has become very complex and problematic these days. As van Berkel and Bos wrote, 'if any form is possible and all are equally functional in an economic sense, the pragmatic, standardised language of Modernism has lost its imperative. A simple, self-evident reasoning no longer justifies any specific form' [16]. The main issue of the organisational model would be then the distribution and classification of information. In principle architectural values, that is both will of subject and base of objectivity, can be manifested by direct and transparent diagrammatic techniques.

Meanwhile in practice models like Seifert-surface, Mobiusstrip or Klein-bottle are often applied and set to be 'developable' by van Berkel, they could also be considered as individualism and increasingly as a cliché. The studio has a few organisational models that can be realised through various ways according to the ever-changing group of target-effects. The result would be usually the duality of a transmitter blob and a functional box, a soft or a cornered fold-structure. Isn't it a universal method then, a digital automation-tool? Van Berkel draws a distinction between himself and those architects who use very consistent and repetitive working methods because he asserts that he has differences in his works. Let's take an example. Daniel Libeskind in his Jewish Museum in Berlin (1988-1999) emphasised the tears of narrative or historic continuity instead of the idea of linearity, universality and totality. There is emptiness between the historical and geometrical differences: the world is seen in pieces. Ten years after of this plan UN Studio rather emphasises the chance that can happen in the interval. Both of these differencebased aspects replaced the chronologic history with the discrete event but while there is an abstract-spiritual 'meaning' in the void, in the building-sized Klein-bottle real data flows. What is more, while Libeskind kept on making crystalline structures in nearly all his projects and tears loosed their meaning as becoming standard aesthetic garniture from the store of the creator, the vanguard of van Berkel shows constancy rather in organisational level and in a kind of 'topographical' way. The nearly constant models are tailored to the program of locality trying to make deeper relations between function, structure and figure. This is nothing more again than making a rhizomatic network of immanence or fulfilling the scaleless architectural images of Cache. (See e.g. 'singular' products of the Mobius-strip model on Fig. 11,)

UN Studio pulls the architect out of traditional design process and, at the same time, the redefined image of it is taken into the focus of attention thanks to diagrammatic communication strategy. Furthermore design technique is not transparent only by diagrams but because of publications. Not just a single postmortem summary of a life-work is published today. The contemporary architect is documenting his or her work parallel with building as it can be seen on DVD-releases of a movie. Discs no. 2, 3 or 4 contain 'behind-the-scenes documentaries' and 'director's audio commentary' about how the movie was made. However, can anything be relevantly explored about the method this way? Why are these explanations needed if both film and building has to operate self-standing? Does the product have higher or lower value if we know a sketch of its genesis? Can publishing be understood as a special mediator between closed territories of practice and theory, as means of 'intended' immanence, when all architects produce as many books as they can? Would be the only goal self-representation then? Additionally, is either the Jewish Museum comprehensible without the helping text of 'Between the lines' or the Mercedes Museum in Stuttgart without its organisational diagrams?

Even if these questions are very complicated and cannot be answered here, it has to be mentioned that in certain fields both the role of architect and design technique has changed in the last decades owing to rigorous regulations, globalization, criticism of post-modern thinking, lack of energy and complexity above all. Deconstructive abstract 'elitism' wanted to be- 


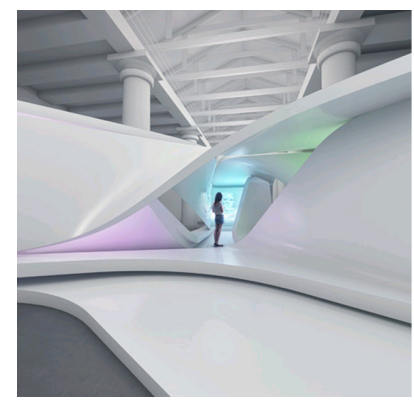

S

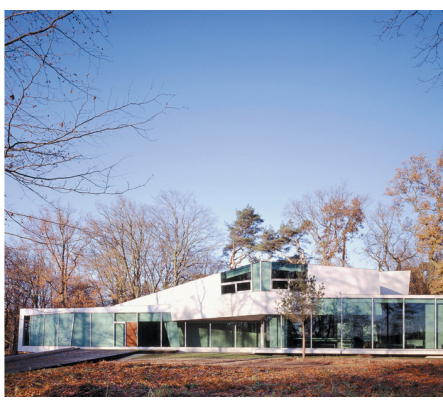

M

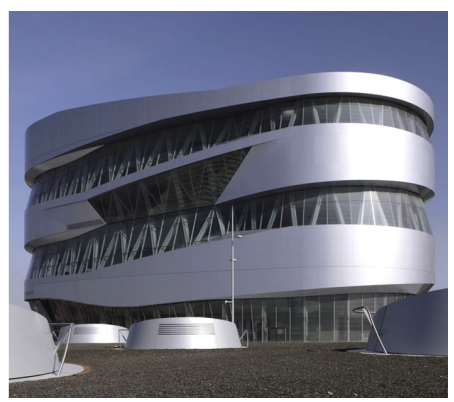

$\mathrm{L}$

Fig. 11. S - 'The Changing Room', M - Möbius-house, L - Mercedes Museum: Montage: Zoltán Bun

come a democratic network of designers in UN Studio. The distinction, conceptualism, autonomy of revolutionary, and at least partly utopian, architectural or artistic position turned to be neutral and useful. Maybe there is nothing new in this shift, it happened back and forth time after time. The importance of 'sensible-to-everyday' or 'reflective' architecture of the Millennium would then be able to follow design process by the computer and the diagram. Hence the process could be comprehensible for decision-makers and a set of optimal solutions can be found. This real-time theory is coupled with the tendency called 'total design' by Hal Foster which is a network of designers who try to watch and handle complexity, instead of being a 'traditional architect'. Thus the director-role of architect does not come to an end but shall become an important knot of the network, even if he is celebrating himself as Foster talks about van Berkel.

\section{References}

1 Betsky A, Unfolding the Forms of UN Studio, UN Studio. UN Fold, NAi Publishers, 2002.

2 Bun Z, Cím nélkül. Libeskind-hiányok Berlinben, Berlin átváltozásai. Város, építészet, kultúra (Kerékgyártó B, ed.), Typotex, Budapest, 2008, pp. 315338.

3 no. $2,10-23$

4 _ Hogyan lett a Folding, avagy ezredvégi épitészetelmélet Cache mestermunkájának tükrében, Utóirat. A Régi-új Magyar Építômúvészet melléklete, 2009, pp. 22-33.

5 Cache B, Earth Moves: The Furnishing of Territories (Ms tr. Anne Boyman, ed.), MIT Press, Cambridge, 1995.

$6 \_$, Digital Semper, Anymore (Cynthia C. Davidson, ed.), Anyone Corporation, New York, 2000, pp. 190-197.

7 Deleuze G, The Fold. Leibniz and the Baroque (Tom Conley, ed.), University of Minnesota Press, Minnesota, 1992.

8 Lootsma B, Superdutch., The Second Modernity of Dutch Architecture, Thames \& Hudson, London / Princeton Architectural Press, New York / DVA, Nijmegen, 2000.

9 Lynn G (ed.), Folding in Architecture, Architectural Design Profile, 1993.

10 Mennan Z, Des Formes Non Standard: Un 'Gestalt Switch', Architectures Non Standard (Migayrou F, Mennan Z, eds.), Editions du Centre Pompidou, Paris, 2003, pp. 34-41.

11 Perella S, Hypersurface-Theory: Architecture Culture, Architectural Design (1998), no. 68, 7-15.

12 Theoretical Meltdown, Architectural Design (2009), no. 1.
13 Stocktaking 2004: Nine Questions About the Present and Future of Design, Harvard Design Magazine (2004), no. 20, 4-52.

14 Somol R, Dummy Text, or the Diagrammatic Basis of Contemporary Architecture, Diagram Diaries, Thames \& Hudson, London, 1999, pp. 6-25.

15 UN Studio, Design Models, Thames \& Hudson, London, 2006. 16 UN Studio, Move, UN Studio \& Goose Press, Amsterdam, 1999. 